groups of people possess some knowledge of nutrition and dietetics are self-evident and require no argument. The Society was convinced at the time that the establishment of courses and an authoritative certificate in nutrition and dietetics would be of benefit to substantial numbers of people. The success of this venture of the Society into the educational field has vindicated that belief, but the Society as such no longer has any responsibility for the teaching or the examinations, which now belongs to the Royal Sanitary Institute, where the work is carried out efficiently and well.

\title{
Nutrition in Hospital Catering
}

\section{By C. C. A. Gibbs, King Edward's Hospital Fund for London School of Hospital} Catering, St. Pancras Hospital, London, N.W.I

\section{Diet and the sick}

It is estimated that in the hospitals of Great Britain there are about half a million patients, and that the staff that looks after them, directly or indirectly, numbers also about half a million. This important section of the public consumes, therefore, about three million meals a day, and in no sphere of catering could it be said that the application of sound nutritional principles was more essential. A proportion of the meals comes within the category of special diets, and as such is the responsibility of the therapeutic dietitian.

It may be asked why hospitals have not led the way in food education, for surely in no more suitable place could people be taught the elementary principles of good feeding. Unfortunately hospitals, far from leading, have until comparatively recently shown little desire to seize the opportunity to advance the knowledge of nutrition. Fortunately, however, nutritionists have taken the initiative and, as a result of their unceasing efforts, hospital authorities have become increasingly conscious of the remedial value of good feeding.

\section{Investigations and reports}

In the campaign for raising the standard of hospital feeding, the King Edward's Hospital Fund for London have taken an active part. In I 943 they undertook, in collaboration with several London hospitals, a survey of the diet provided for patients and staff; details of the survey were given in their first memorandum on hospital diet published that year, the main purpose of which was to draw the attention of the authorities to the need for reviewing the diet provided in hospitals, in the light of recent advances in the science of nutrition.

Encouraged by the interest taken by the hospitals, and in the light of further study of the many problems presented, the Fund published, in 1945, a second memorandum, which dealt in greater detail with the whole organization of the catering department, one of its main recommendations being that catering in all its processes should be regarded as a separate department of the hospital, in the 
charge of an experienced caterer, preferably one who was also a qualified dietitian. Unfortunately very few individuals possessed the dual qualification, and hospitals have appointed either qualified caterers responsible for the general feeding of patients and staff or dietitians working under the orders of the physicians and surgeons and responsible for the preparation and service of special diets. The dietitian also advises patients discharged from hospitals on their diets at home and similarly advises patients in out-patient clinics. In many hospitals the dietitian and caterer give talks to medical and nursing students and other groups, and it is in those hospitals that one sees some of the fruits of education in nutrition.

It may be said, therefore, that education in nutrition in hospitals has developed with the appointment of whole-time caterers and dietitians, whose responsibility it has become, with the collaboration and support of their catering committees and the medical staff, to teach the importance of nutritionally balanced meals.

In hospitals there are two main groups to be catered for, the patients and the staff. The dietary for the former may be classed as full, light or special, but whichever it is, the therapeutic value of the diet cannot be overestimated.

\section{Hospital staff}

It is the practice in this country for the nursing staff to be responsible for serving meals to the patients; thus, if the patients are to receive any education in nutrition, it must largely be from advice and guidance given by the nurses, who have to depend on the catering officers for demonstrations of the results of their nutritional knowledge. It is easy to see, therefore, how a weak link in the chain of nutritional responsibility can retard a patient's recovery and seriously endanger his future prospects of good health. One has only to witness the remarkable recovery of some patients, when this is due almost exclusively to the care taken over their diet, to realize the vital part nutrition can play in medical and surgical practice.

The second hospital group to be catered for is the staff, normally active and healthy. Mostly they have good appetites; a large proportion of them are young and their work is hard and exacting. Their feeding is, therefore, of the utmost importance; if bodily vigour is to be maintained, it can only be by ensuring that the meals provided are adequate, well balanced and appetising.

\section{Refresher courses}

Unfortunately all too few of the staff employed in hospital kitchens have received adequate training; further, the supply of suitably trained caterers is limited. Until the situation is remedied, feeding standards are bound to remain below the desirable level. The seriousness of these deficiencies has been apparent in almost all the surveys carried out by the King's Fund during the past few years. In their efforts to help hospitals the Fund's representatives decided to establish a School of Hospital Catering, the first of its kind in this country. It was considered that initially the most urgent need was to provide short-term refresher courses, because owing to the shortage of trained staff hospitals would have difficulty in releasing 
any of them for long periods of training. Courses were planned for three categories, catering officers, head chefs and senior cooks, cooks and assistant cooks; since September 195I, when the School opened, some 250 students have attended.

The Catering Officers' course is of ro days' duration and covers all aspects of hospital catering. Only a small minority of those attending are dietitians, but the interest shown in nutrition has been most encouraging. No practical cookery is undertaken by this group, but the syllabus includes three sessions on nutrition covering fundamental principles of nutrition and their application to the food requirements of patients and staff, composition and nutritive value of various foods, the effect of cooking on the different nutrients and nutrition as a factor in maintaining health. Besides these sessions, opportunities are given for discussion, and full use is made of a small technical library, which includes well-known works on nutrition and dietetics. Other subjects in the syllabus, such as administration, menu planning, ration allowances and priorities, have as an underlying theme the practical application of nutrition in hospital feeding. Attention is drawn to these matters also when visiting the catering departments, including special diet kitchens, of other hospitals-another feature of the courses.

The Head Chefs' course is of 12 days' duration, and the syllabus follows the main lines of the Catering Officers' course, with the addition of practical work in the instructional kitchen at the School and at selected hospitals. The time devoted to the study of nutrition is the same in both courses.

The interest shown in nutrition by these two groups of students is most encouraging; at the moment modifications of the syllabus to allow more time for nutrition are being considered.

The Cooks' and Assistant Cooks' course lasts 4 weeks and has been designed primarily to assist those who have had little or no basic training in cookery. The syllabus consists mainly of practical work, and instruction is given in the elemenatry principles of nutrition. Such has been the interest that many students have requested information as to how they can continue to improve their practical knowledge of the subject.

\section{Bursaries}

Last year a bursary scheme for the training of hospital catering officers was sponsored by the Fund. Candidates trained in domestic science with experience in various fields of catering were selected; the course, of I year's duration, began in September 1952.

The syllabus is split into four parts, practice and theory at the School, practical cookery in selected hospitals and butchery training, administrative training in selected hospitals and experience as Assistant Catering Officer in selected hospitals.

While the students are at the School, the study of nutrition is given prominence, and all practical cookery is closely related to the theory sessions. Students are expected also to give practical cookery demonstrations, for it is essential that as catering officers they should be able to impart their knowledge in a practical way to untrained staff. 
All who are in any way connected with hospitals will appreciate that there is still much cause for dissatisfaction in the field of nutrition. The training of suitable staff and the recognition of their status must be relentlessly pursued if success is to be achieved. All the same, it is true to say that nutrition, with its many practical applications, has become a vital factor in hospital catering, and that fact must justify the hope that hospitals will in time lead the way in food education.

\section{The Teaching of Nutrition : A Summary}

\section{By John YudкIn, Queen Elizabeth College, London, W.8}

To-day's proceedings have shown that nutrition education can take place at three levels. The first is as an essential part of general education in living by the universal inculcation of sound nutritional habits. The second is in teaching nutrition for crafts and professions concerned in applying nutritional knowledge in practice, cooks, caterers, agriculturalists, doctors and particularly dietitians. The third is in the training of professional nutritionists.

We have seen that the first problem is mainly the concern of the school teacher. In so far as there is nowadays an extensive school meals service, it is possible to give, mainly by example, practical guidance in the establishment of sound nutritional habits and even to use the opportunity to teach elementary nutritional principles. The fact that such teaching is continued in later school life in association with the teaching of housecraft, however, means that the older boys are not influenced in the same way as the girls. The question of filling the gap might well be considered by those responsible for the teaching of nutrition in schools.

In most of the discussion on the teaching of nutrition as part of a craft or profession it has generally been agreed that the best way is to include it as part of the practical training and not as a separate subject. Cooks and caterers should be taught nutrition while being taught the handling and preparation of food; doctors should receive nutritional instruction in the wards and clinics. The difficulty, however, is that at present those who teach nutrition are themselves not sufficiently well trained in the subject. There is thus, for example, a tendency for domestic science teachers to learn their nutrition from other domestic science teachers, so that there is inevitably a perpetuation of ill-founded, inaccurate and out-of-date information from generation to generation.

Similarly, medical students, if taught nutrition at all, will be taught by the few clinicians who have an interest in the subject but whose own knowledge, to judge from letters in the medical journals, is not always necessarily sound. Again, as we have heard, students in technical schools can learn either from experts in the crafts of food preparation or food technology, who have little nutritional training, or from academically minded chemists or biologists, who may not have the ability to implant essential nutritional information at an appropriate non-academic level. 